\title{
Efficacy of two predatory phytoseiid mites in controlling the western flower thrips, Frankliniella occidentalis (Pergande) (Thysanoptera: Thripidae) on cherry tomato grown in a hydroponic system
}

Nevin Ahmed ${ }^{1,2^{*}}$ and Ming Lou ${ }^{3}$

\begin{abstract}
Thrips is one of the most harmful insect groups attacking many field and vegetable crops. Predatory mites, especially those in family Phytoseiidae, are considered as good bioagents to control thrips where application of chemical pesticides can be decreased. This work was conducted to evaluate the efficacy of the two phytoseiid mites, Amblyseius swirskii (Athias-Henriot) and Neoseiulus cucumeris (Oudemans), in controlling the western flower thrips (Frankliniella occidentalis, Pergande) on cherry tomato plants in a hydroponic system. The results indicated that both predatory mites were effective in decreasing populations of adults and larvae of $F$. occidentalis at all of the chosen periods. The mixed effect of $A$. swirskii plus $N$. cucumeris (AS $+N C$ ) was higher in reducing thrips populations than that when each of them was used alone. Larvae of $F$. occidentalis were decreased on leaves of tomato plants from 11.2 and 14.5/leaf in the control treatment (no predatory mites) to 4.27 and 3.73/leaf due to the combination of AS and NC after 7 and 15 days, respectively. On the other hand, larvae of F. occidentalis attained levels of 8.75 and 12.83/ five flowers when no predatory mites were applied compared to 2.46 and 1.20/five flowers when adults of AS plus NC were used after 50 and 60 days of releasing, respectively. This study demonstrated that the combination of AS and NC resulted in higher reductions in $F$. occidentalis without any competition between them.
\end{abstract}

Keywords: Biological control, Frankliniella occidentalis, Predatory phytoseiid mites, Greenhouse, Hydroponic conditions

\section{Background}

Tomato is one of the most important vegetable crops and its fruit production reaches about $164 \times 10^{6}$ million tons from $4.7 \times 10^{6}$ ha around the world (FAOSTAT, 2015). Using chemical methods for controlling pests such as western flower thrips Frankliniella occidentalis (Pergande) is not sustainable because of their high costs and risks on non-target organisms and environmental systems (Herron et al., 2007). F. occidentalis is one of the serious polyphagous and cosmopolitan insect pests

\footnotetext{
* Correspondence: nevin.ahmed@fagr.bu.edu.eg

${ }^{1}$ Department of Plant Protection, Faculty of Agriculture, Benha University, Benha, Egypt

${ }^{2}$ Department of Plant Protection, Huazhong Agricultural University, Wuhan, Hubei, China

Full list of author information is available at the end of the article
}

with marked harmful and adverse effects on flowers and fruits to over 200 host plants (Yang et al., 2015). It has also a high resistance to insecticides (about 163 cases) among more than 26 active chemical ingredients around the world (Bielza et al., 2007 and Wang et al., 2011). Larvae and adults of $F$. occidentalis have a high affinity level to attack aboveground organs of crops, especially buds, fruits, and young leaves (Venette and Davis, 2004). F. occidental injury can range from deformation and shifting for plant colors from bronze to black to heavy infections with lessening, dwarfed and defoliation of leaves, and detached petioles from the plant stem. Moreover, F. occidentalis is a vector of many plant viruses such as maize chlorotic mottle virus, impatiens necrotic spot virus, and tomato spotted wilt virus (Webster et al., 2011 and Zhao et al., 2014). Populations 
of $F$. occidentalis can rapidly rebound from insecticide applications due to its high fecundity, haplotype genetics, and short generation time (Gao et al., 2012). It is difficult to control $F$. occidentalis with insecticides because it deposits its eggs inside plant tissues and the adults and larvae feed in concealed locations such as flower buds, which protected them from insecticide effects (Brodsgaard, 2004). Thus, an urgent requirement is strongly needed for the biological control strategy.

Phytoseiid mites (Acarina: Phytoseiidae) are vital polyphagous predators and have got a great attention to be applied as bio-control agents or as alternative approaches to pesticides against $F$. occidentalis on different plants such as vegetable, fruit, and ornamental crops under both greenhouse and field conditions (Jacobson et al., 2001; van Houten et al., 2005 and Messelink et al., 2006). These predatory mites have been successfully used against several pests, including spider mites, whitefly, and thrips (Chow et al., 2010; Fouly et al., 2011 and Kakkar et al., 2016) but their beneficial effects in managing F. occidentalis (Thysanoptera: Thripidae) on tomato plants have not been evaluated thoroughly and are needed to be reported. Therefore, this study aimed to evaluate the efficacy of the two phytoseiid predatory Typhlodromips (Amblyseius) swirskii and Neoseiulus cucumeris in controlling F. occidentalis on cherry tomato plants grown under a hydroponic system.

\section{Materials and methods}

\section{Cultures of mites and thrips}

Both predatory mite colonies were obtained from a citrus orchard located at Huazhong Agricultural University, Wuhan, Hubei, China, in February 2015. Both mites were reared and maintained on Tyrophagus putrescentiae (Schrank) as a food source in an environmental chamber at $25 \pm 1{ }^{\circ} \mathrm{C}$ and $70 \pm 5 \% \mathrm{RH}$ and photoperiod of L16:D8 h. F. occidentalis was obtained from a commercial tomato field and then maintained on pods and leaves of kidney beans (Phaseolus vulgaris L.) in sterilized glass jars according to Arthurs and Heinz (2002). The jars were closed by plastic films which contained $2-3-\mathrm{cm}$ holes covered with fine meshes for ventilation. The rearing jars were placed in an environmental chamber at 26 $\pm 2{ }^{\circ} \mathrm{C}, 65 \pm 5 \% \mathrm{RH}$ and photoperiod of L13:D11 $\mathrm{h} \pm 1$.

\section{Experimental design}

The experiments were conducted at Hubei Academy of Agricultural Sciences, Wuhan, Hubei Province, China, from March 1, 2015, to May 15, 2015, in cages $(0.5 \mathrm{~m}$ length $\times 0.5 \mathrm{~m}$ width $\times 1.5 \mathrm{~m}$ height) covered with nylon mesh under greenhouse conditions using cherry tomato (Solanum lycopersicum) as an indicator plant. Strong tomato seedlings at age of 15 days were prepared, transferred, and then grown in a hydroponic system. Each cage contained five pots and each pot had two tomato seedlings. Hoagland's solution was used in the current experiment as a nutrient source for tomato plants.

\section{First experiment}

This experiment had four treatments with five replicates each: T1 (control without predatory mites), T2 (adults of A. swirskii), T3 (adults of N. cucumeris), and T4 (adults of $A$. swirskii plus $N$. cucumeris). The experimental cages were arranged in blocks and randomly assigned. The released numbers of predatory mites were 30 (10 males +20 females) per plant, while the initial numbers of $F$. occidentalis for each plant were 60 adults. Both thrips and predatory mites were released one time at the beginning of the experiment. Predatory mites were released onto plants after $24 \mathrm{~h}$ from adding adults of thrips. Leaves of tomato plants were checked six times (after 7, $15,30,45,60$, and 75 days), while their flowers were only examined two times (after 50 and 60 days) from the transporting of tomato seedlings. Leaves (2-5) and flowers (5-8) of tomato were collected from each plant in separate Ziploc bags $(17 \times 22 \mathrm{~cm})$ from each plant and then transferred to the laboratory. The leaves and flowers of tomato were placed in a plastic cup with ethanol (75\%: diluted from analytical ethanol grade $99 \%)$ for $30 \mathrm{~min}$ to displace the different stages of thrips. Numbers of thrips (larvae and adults) per leaf and per five flowers were counted using a magnifier lens.

\section{Second experiment}

This experiment was conducted under the same conditions as described above with two treatments in five replicates for each one, T1 (A. swirskii) and T2 ( $N$. cucumeris), to evaluate densities of their different stages (egg, immature, and adult) on leaves and flowers of cherry tomato infested by $F$. occidentalis. The initial numbers of $F$. occidentalis for each plant were 60 adults. The released numbers of these predatory mites were 30 (10 males +20 females). Numbers of eggs, immature stages, and adults for A. swirskii and N. cucumeris were counted six times as mentioned above on each leaf and only two times for every five flowers after their release by a dissecting microscope.

\section{Data analysis}

The statistical analysis of experimental data was performed with one-way ANOVA using SPSS 18.0 followed by Tukey's test to evaluate the significant differences between treatments at $P<0.05$.

\section{Results and discussion}

Controlling $F$. occidentalis with the predatory mites

Data in Table 1 showed that numbers of $F$. occidentalis larvae and adults on tomato leaves were highly affected 
Table 1 Mean numbers ( \pm SE) of Frankliniella occidentalis per leaf of tomato after releasing adults of Amblyseius swirskii and Neoseiulus cucumeris at different periods (days)

\begin{tabular}{|c|c|c|c|c|c|c|c|}
\hline \multirow[b]{2}{*}{ Treatments } & & \multicolumn{6}{|c|}{ Experimental intervals (days) } \\
\hline & & 7 & 15 & 30 & 45 & 60 & 75 \\
\hline CK & Larvae & $11.2 \pm 2.03 a$ & $14.5 \pm 1.98 \mathrm{a}$ & $19.6 \pm 3.15 \mathrm{a}$ & $12.3 \pm 2.83 a$ & $9.93 \pm 1.87 \mathrm{a}$ & $5.47 \pm 1.01 \mathrm{a}$ \\
\hline AS & & $7.09 \pm 0.97 c$ & $6.16 \pm 1.13 b$ & $5.58 \pm 0.65 b$ & $4.81 \pm 0.29 b$ & $3.95 \pm 0.45 c$ & $2.70 \pm 0.23 b$ \\
\hline NC & & $8.14 \pm 0.88 b$ & $7.69 \pm 1.34 b$ & $6.04 \pm 0.58 b$ & $5.48 \pm 0.47 b$ & $4.93 \pm 0.38 b$ & $3.58 \pm 0.54 b$ \\
\hline$A S+N C$ & & $4.27 \pm 0.56 \mathrm{~d}$ & $3.73 \pm 0.67 d$ & $3.11 \pm 0.45 c$ & $2.34 \pm 0.32 c$ & $1.86 \pm 0.23 \mathrm{~d}$ & $1.24 \pm 0.28 \mathrm{e}$ \\
\hline CK & Adults & $5.41 \pm 0.72 \mathrm{a}$ & $6.27 \pm .68 \mathrm{a}$ & $7.97 \pm 1.01 \mathrm{a}$ & $7.03 \pm 0.81 a$ & $6.25 \pm 0.76 a$ & $4.09 \pm 0.61 \mathrm{a}$ \\
\hline AS & & $4.09 \pm 0.35 b$ & $2.74 \pm 0.26 b$ & $2.28 \pm 0.35 c$ & $1.86 \pm 0.24 c$ & $1.49 \pm 0.34 c$ & $1.15 \pm 0.16 c$ \\
\hline NC & & $4.28 \pm 0.41 b$ & $3.04 \pm 0.44 b$ & $2.86 \pm 0.47 b$ & $2.56 \pm 0.39 b$ & $2.19 \pm 0.32 b$ & $1.77 \pm 0.22 b$ \\
\hline$A S+N C$ & & $3.67 \pm 0.52 b$ & $2.16 \pm 0.31 c$ & $1.73 \pm 0.29 d$ & $1.21 \pm 0.24 \mathrm{~d}$ & $1.00 \pm 0.18 d$ & $0.85 \pm 0.11 c$ \\
\hline
\end{tabular}

Means followed by same letters within columns are not significantly different $(P<0.05$, Tukey's HSD)

CK control, AS Amblyseius swirskii, NC Neoseiulus cucumeris, AS + NC Amblyseius swirskii + Neoseiulus cucumeris and SE standard error

by the presence of both $A$. swirskii and $N$. cucumeris mites after different exposure periods. It was clear from these results that using $A$. swirskii and $N$. cucumeris caused higher reductions in $F$. occidentalis larvae and adults than in control treatments (no mites). By increasing experimental times, larvae and adults of F. occidentalis declined, while their lowest values were observed after 60 and 70 days of transferring tomato seedlings in the hydroponic pots. Using A. swirskii in combination with $N$. cucumeris led to greater reductions in $F$. occidentalis larvae and adults than single applications. The effect of $A$. swirskii was higher than that of N. cucumeris. At 7 days, larvae of $F$. occidentalis decreased from 11.2/leaf in the control to 4.27, 7.09, and 8.14 individuals/leaf in the A. swirskii plus N. cucumeris, A. swirskii, and $N$. cucumeris treatments, respectively. Thrips adults (at 7 days from transferring the tomato seedlings to the cages) were decreased from 5.41/leaf under no mite present to $3.67,4.09$, and 4.28 individuals/leaf after using adults of $A$. swirskii plus $N$. cucumeris, A. swirskii, and $N$. cucumeris, respectively. At the end of the experimental study, numbers of larvae and adults of $F$. occidentalis were obviously decreased from 5.47 and 4.09/leaf in the control to 1.24 and 0.85 , to 2.70 and 1.15 / leaf, and to 3.58 and $1.77 /$ leaf in the A. swirskii plus $N$. cucumeris, each of $A$. swirskii and $N$. cucumeris treatments, respectively.

Data presented in Table 2 showed the effect of different treatments on populations of larvae and adults of $F$. occidentalis on flowers of cherry tomato after 50 days from its transfer to the hydroponic containers. The results indicated the positive role of predatory mites (A. swirskii plus $N$. cucumeris, each of $A$. swirskii and $N$. cucumeris) in controlling F. occidentalis. Also, using both showed better patterns in reducing the populations of larvae and adults of $F$. occidentalis than using either A. swirskii or $N$. cucumeris alone. At 50 days (when flowers of tomato appeared or opened), the highest values of larvae and adults of $F$. occidentalis (8.75 and 4.19 individuals/ five flowers) were recorded in the control treatments (no predatory mites). In contrast, the lowest populations of larvae and adults of $F$. occidentalis (2.46 and 1.68 individuals/five flowers) were found when adults of A. swirskii plus $N$. cucumeris were released. After 60 days, larvae and adults of $F$. occidentalis averaged 12.83 and 7.11 individuals/five flowers, respectively, and then reached their lowest values (1.21 and 0.89 individuals/five flowers) after releasing adults of $A$. swirskii plus N. cucumeris.

The current study showed marked reductions in populations of larvae and adults of western flower thrips due to using predatory mites at different intervals. Shipp and Wang (2003) found that populations of F. occidentalis after the release of $A$. cucumeris under greenhouse conditions were significantly decreased to lower values $(63.6$ thrips per plant as a result of $A$. cucumeris releasing) compared to the control. (averaged 283.8 thrips per plant). Therefore, it can be easily noted that the decrease in thrips numbers could coincide with the presence of this predatory mite.

It was clear from the current investigation that $A$. swirskii and $N$. cucumeris were differed in their

Table 2 Mean numbers ( $\pm \mathrm{SE}$ ) of Frankliniella occidentalis per five flowers of tomato after releasing adults of Amblyseius swirskii and Neoseiulus cucumeris at different periods (days)

\begin{tabular}{llllll}
\hline Treatments & \multicolumn{2}{l}{ Larvae } & \multicolumn{3}{l}{ Adults } \\
\cline { 2 - 3 } \cline { 5 - 6 } & 50 days & 60 days & & 50 days & 60 days \\
\hline CK & $8.75 \pm 1.89 \mathrm{a}$ & $12.83 \pm 2.34 \mathrm{a}$ & $4.19 \pm 0.33 \mathrm{a}$ & $7.11 \pm 0.79 \mathrm{a}$ \\
$\mathrm{AS}$ & $3.15 \pm 0.54 \mathrm{c}$ & $2.10 \pm 0.31 \mathrm{c}$ & & $1.94 \pm 0.42 \mathrm{~b}$ & $1.36 \pm 0.11 \mathrm{~b}$ \\
$\mathrm{NC}$ & $4.07 \pm 0.46 \mathrm{~b}$ & $3.24 \pm 0.57 \mathrm{~b}$ & & $2.21 \pm 0.26 \mathrm{~b}$ & $1.85 \pm 0.18 \mathrm{~b}$ \\
AS + NC & $2.46 \pm 0.23 \mathrm{c}$ & $1.20 \pm 0.24 \mathrm{~d}$ & & $1.68 \pm 0.17 \mathrm{~b}$ & $0.89 \pm 0.10 \mathrm{~b}$
\end{tabular}

Means followed by same letters within columns are not significantly different $(P<0.05$, Tukey's HSD)

CK control, AS Amblyseius swirskii, NC Neoseiulus cucumeris, AS + NC Amblyseius swirskii + Neoseiulus cucumeris and SE standard error 
capabilities to control $F$. occidentalis on tomato plants, where A. swirskii was more efficient as a bioagent than $N$. cucumeris. These findings are similar to those obtained by van Houten et al. (2005) who found that the release of $A$. swirskii led to a better establishment and superior for $F$. occidentalis control on sweet pepper over 6 weeks compared with $N$. cucumeris. Arthurs et al. (2009) also showed that A. swirskii and N. cucumeris were good and effective predators for Scirtothrips dorsalis on sweet pepper but the efficiency of $N$. cucumeris was less than A. swirskii. Similarly, Stansly and Castillo (2010) observed low efficiency in controlling whiteflies and broad mites by $N$. cucumeris as compared with $A$. swirskii on eggplant and pepper under field conditions in south Florida. Moreover, Lee and Gillespie (2011) demonstrated that $A$. swirskii in the Mediterranean region with an optimum temperature for survival and growth might have better adaptation to this local temperature than $N$. cucumeris. Kakkar et al. (2016) found that A. swirskii was more effective in diminishing Thrips palmi (Karny) populations than N. cucumeris on cucumber leaves. So, we could suggest that $A$. swirskii had a higher adaption for the greenhouse conditions than $N$. cucumeris under the hydroponic system. However, some other studies showed different patterns than the current results. Arevalo et al. (2009) found that N. cucumeris or A. swirskii were not efficient in controlling F. schultzei (Trybom) that attacked pepper and blueberry flowers. They explained the low inability of $N$. cucumeris or $A$. swirskii to control F. schultzei by the low presence of mites on flowers of the infested plants. Also, Kakkar et al. (2016) showed that $N$. cucumeris and A. swirskii were effective under shade house and field trial against T. palmi on cucumber leaves, but failed to control F. schultzei in its flowers.

Combination of the used predatory mites (A. swirskii and $N$. cucumeris) showed large reductions in population of larvae and adults of $F$. occidentalis on leaves and flowers of tomato plants that were grown in hydroponic conditions. These findings are in harmony with the results of Chow et al. (2010) who recorded that mixing predators led to higher enhancements in controlling different species of thrips on many crops.

\section{Populations of predatory mites preying on $F$. occidentalis}

The presented results showed that numbers of eggs, immature stages, and adults of A. swirskii and N. cucumeris were highly enhanced with the increase of the experimental periods to 45 days. Numbers of $A$. swirskii were higher than those of $N$. cucumeris on both leaves and flowers of cherry tomato plants that were attacked by adults of $F$. occidentalis (Tables 3 and 4). Numbers of A. swirskii and $N$. cucumeris on leaves of tomato plants were greater than those on their flowers. On the leaves
Table 3 Density of different stages ( \pm SE) of Amblyseius swirskii per leaf of tomato after feeding on Frankliniella occidentalis at different periods (days)

\begin{tabular}{llll}
\hline Experimental days & Egg & Immature & Adults \\
\hline 7 & $0.83 \pm 0.07 \mathrm{f}$ & $2.13 \pm 0.25 \mathrm{e}$ & $2.61 \pm 0.31 \mathrm{~d}$ \\
15 & $1.79 \pm 0.21 \mathrm{e}$ & $5.37 \pm 0.61 \mathrm{~d}$ & $6.21 \pm 0.59 \mathrm{c}$ \\
30 & $4.83 \pm 0.48 \mathrm{~d}$ & $7.98 \pm 0.76 \mathrm{c}$ & $10.84 \pm 2.45 \mathrm{~b}$ \\
45 & $6.91 \pm 0.69 \mathrm{a}$ & $12.07 \pm 3.10 \mathrm{a}$ & $14.16 \pm 3.56 \mathrm{a}$ \\
60 & $5.65 \pm 0.71 \mathrm{~b}$ & $11.22 \pm 2.34 \mathrm{a}$ & $13.00 \pm 3.27 \mathrm{a}$ \\
75 & $5.09 \pm 0.46 \mathrm{c}$ & $9.51 \pm 2.15 \mathrm{~b}$ & $10.75 \pm 2.78 \mathrm{~b}$ \\
\hline
\end{tabular}

Means followed by same letters within columns are not significantly different $(P<0.05$, Tukey's HSD $)$

$S E$ standard error

of tomato, counts of eggs, immature stages, and adults for A. swirskii ranged from $0.83,2.13$, and 2.61 / leaf to $5.09,9.51$, and $10.75 /$ leaf, respectively, while stages of $N$. cucumeris varied from $0.61,1.76$, and 2.14 /leaf to $4.18,7.42$, and 9.26/leaf, respectively, when the experimental period increased from 7 to 75 days. Data in Table 5 showed that feeding of $A$. swirskii on $F$. occidentalis that attacked flowers of tomato plants caused marked enhancements in the numbers of its eggs, immature stages, and adults from $0.89,2.03$, and 2.69 /five flowers after 50 days to $1.40,3.71$, and 5.80 /five flowers after 60 days, respectively. Moreover, noticeable increases were recorded in eggs, immature stages, and adults of $N$. cucumeris from $0.78,1.63$, and $2.37 /$ five flowers after 50 days to $1.26,2.84$, and 4.60/five flowers after 60 days, respectively, after using $F$. occidentalis as a prey.

The current investigation clearly showed that counts of eggs, immature stages, and adults of $A$. swirskii and $N$. cucumeris after attacking $F$. occidentalis on leaves and flowers of tomato were highly enhanced and they were higher for $A$. swirskii than for $N$. cucumeris at the chosen experimental periods from 7 to 75 days on leaves and from 50 to 60 days on flowers after transferring seedlings of tomato to the hydroponic containers. The higher increases in populations of $A$. swirskii than $N$. cucumeris might be related to its better adaptation under

Table 4 Density of different stages ( \pm SE) of Neoseiulus cucumeris per leaf of tomato after feeding on Frankliniella occidentalis at different periods (days)

\begin{tabular}{llll}
\hline Experimental days & Egg & Immature & Adults \\
\hline 7 & $0.61 \pm 0.06 \mathrm{~d}$ & $1.76 \pm 0.26 \mathrm{e}$ & $2.14 \pm 0.32 \mathrm{~d}$ \\
15 & $1.33 \pm 0.11 \mathrm{c}$ & $4.83 \pm 0.37 \mathrm{~d}$ & $5.39 \pm 0.71 \mathrm{c}$ \\
30 & $3.70 \pm 0.24 \mathrm{~b}$ & $6.52 \pm 0.84 \mathrm{c}$ & $9.40 \pm 1.48 \mathrm{~b}$ \\
45 & $5.30 \pm 0.56 \mathrm{a}$ & $10.91 \pm 1.87 \mathrm{a}$ & $12.08 \pm 2.51 \mathrm{a}$ \\
60 & $4.98 \pm 0.63 \mathrm{a}$ & $9.34 \pm 2.11 \mathrm{~b}$ & $11.7 \pm 1.93 \mathrm{a}$ \\
75 & $4.18 \pm 0.49 \mathrm{~b}$ & $7.42 \pm 0.86 \mathrm{c}$ & $9.26 \pm 1.06 \mathrm{~b}$ \\
\hline
\end{tabular}

Means followed by same letters within columns are not significantly different $(P<0.05$, Tukey's HSD)

SE standard error 
Table 5 Density of different stages $( \pm \mathrm{SE}$ ) of predatory mites per five flowers of tomato after their feeding on Frankliniella occidentalis at different experimental periods (days)

\begin{tabular}{lllll}
\hline $\begin{array}{l}\text { Experimental } \\
\text { days }\end{array}$ & $\begin{array}{l}\text { Predatory } \\
\text { mites }\end{array}$ & Egg & Immature & Adults \\
\hline 50 & $\begin{array}{l}\text { Amblyseius } \\
\text { swirskii }\end{array}$ & $0.89 \pm 0.04 \mathrm{~b}$ & $2.03 \pm 0.21 \mathrm{~b}$ & $2.69 \pm 0.31 \mathrm{~b}$ \\
60 & & $1.40 \pm 0.13 \mathrm{a}$ & $3.71 \pm 0.35 \mathrm{a}$ & $5.80 \pm 0.65 \mathrm{a}$ \\
50 & $\begin{array}{l}\text { Neoseiulus } \\
\text { cucumeris }\end{array}$ & $0.78 \pm 0.23 \mathrm{~b}$ & $1.63 \pm 0.15 \mathrm{~b}$ & $2.37 \pm 0.24 \mathrm{~b}$ \\
60 & & $1.26 \pm 0.11 \mathrm{a}$ & $2.84 \pm 0.27 \mathrm{a}$ & $4.60 \pm 0.51 \mathrm{a}$
\end{tabular}

Means followed by same letters within columns are not significantly different $(P<0.05$, Tukey's HSD)

$S E$ standard error

the experimental conditions. The results of the current experiment differed than the findings of Kakkar et al. (2016) who found that eggs and motile stages of $A$. swirskii were higher than those of $N$. cucumeris only on leaves of treated plants, while no eggs and motile stages were observed on flower samples.

\section{Conclusions}

This study shows the effective roles of A. swirskii and $N$. cucumeris in controlling western flower thrips that infests cherry tomato plants under a hydroponic system. Results clearly indicated that $A$. swirskii was more efficient than $N$. cucumeris as a bio-control agent against larvae and adults of $F$. occidentalis. Mixing A. swirskii and $N$. cucumeris was responsible for the highest governing effect on F. occidentalis. So, use of $A$. swirskii plus $N$. cucumeris to control thrips is highly recommended.

\section{Acknowledgements}

The authors are very grateful to the laboratories of Pest Management at Hubei Academy of Agricultural Sciences and Huazhong Agricultural University, Wuhan, Hubei Province, China, for their technical and financial supports. We also thank the editor, associate editor, and anonymous reviewers for their valuable and helpful comments to improve the quality of the manuscript.

\section{Funding}

The experimental work was financially supported by Huazhong Agricultural University.

\section{Availability of data and materials}

All data are available at the end of the article and the materials used in this work are of high quality and grade.

\section{Significant statement}

This study is very helpful for entomologist and acarologist researchers because it provides marked information about the control effect of Amblyseius swirskii and Neoseiulus cucumeris for F. occidentalis on cherry tomato grown under a hydroponic system.

\section{Authors' contributions}

NA designed and set up the experiments, and after that, she analyzed the data and wrote the article. ML conducted the experiment and wrote and revised the article. Both authors read and approved the final manuscript.

\section{Ethics approval and consent to participate}

All experimental works were approved by College of Plant Science and Technology at Huazhong Agricultural University, Wuhan, Hubei, China.

\section{Consent for publication}

The agreement of publication was taken, and as a corresponding author, I confirm that.

\section{Competing interests}

The authors declare that they have no competing interests.

\section{Publisher's Note}

Springer Nature remains neutral with regard to jurisdictional claims in published maps and institutional affiliations.

\section{Author details}

${ }^{1}$ Department of Plant Protection, Faculty of Agriculture, Benha University, Benha, Egypt. ${ }^{2}$ Department of Plant Protection, Huazhong Agricultural University, Wuhan, Hubei, China. ${ }^{3}$ Department of Vegetables Production, Hubei Academy of Agricultural Sciences, Wuhan, China.

Received: 6 September 2017 Accepted: 6 December 2017

Published online: 22 February 2018

\section{References}

Arevalo HA, Fraulo AB, Liburd OE (2009) Management of flower thrips in blueberries in Florida. Florida Entomol 92:14-17

Arthurs S, Heinz KM (2002) In vivo rearing of Thripinema nicklewoodi (Tylenchida: Allantonematidae) and prospects as a biological control agent of Frankliniella occidentalis (Thysanoptera: Thripidae). J Econom Entomol 95:668-674

Arthurs S, McKenzie CL, Jianjun C, Dogramaci M, Brennan M, Houben K, Osborne S (2009) Evaluation of Neoseiulus cucumerisand Amblyseius swirskii (Acari: Phytoseiidae) as biological control agents of chilli thrips, Scirtothrips dorsalis (Thysanoptera: Thripidae) on pepper. Biol Control 49:91-96

Bielza P, Quinto V, Contreras J, Torné M, Martín A, Espinosa PJ (2007) Resistance to spinosad in the western flower thrips, Frankliniella occidentalis (Pergande), in greenhouses of south-eastern Spain. Pest Manag Sci 63:682-687

Brodsgaard HF (2004) Biological control of thrips on ornamental crops. In: Heinz KM, Van Driesche RG, Parrella MP (eds) BioControl in protected culture. Ball Publishing, Batavia, IL, pp 253-264

Chow A, Chau A, Heinz KM (2010) Compatibility of Amblyseius (Typhlodromips) swirskii (Athias-Henriot) (Acari: Phytoseiidae) and Orius insidiosus (Hemiptera: Anthocoridae) for biological control of Frankliniella occidentalis (Thysanoptera: Thripidae) on roses. Biol Control 53:188-196

FAOSTAT 2015. Food and agriculture Organization of the United Nations. http:// faostat3.fao.org/download/Q/QC/E

Fouly AH, Al-Deghairi MA, Abdel Baky NF (2011) Effect of crowding and food level on the biology of Typhlodromips swirskii (Acari: Gamasida: Phytoseiidae) fed on whitefly Bemisia tabaci (Homopetra: Aleyrodidae). J Entomol 8:52-62

Gao YL, Lei ZR, Reitz SR (2012) Western flower thrips resistance to insecticides: detection, mechanisms and management strategies. Pest Manag Sci 68: $1111-1121$

Herron G, Broughton S, Clift A (2007) Frankliniella occidentalis Pergande (Thysanoptera: Thripidae) chemical control: residues associated with the three consecutive spray strategy. Aus J Entomol 46:146-151

Jacobson RJ, Croft P, Fenlon J (2001) Suppressing establishment of Frankliniella occidentalis Pergande (Thysanoptera: Thripidae) in cucumber crops by prophylactic release of Amblyseius cucumeris Oudemans (Acarina: Phytoseiidae). Biocont Sci Technol 11:27-34

Kakkar G, Kumar V, Seal DR, Liburd OE, Stansly PA (2016) Predation by Neoseiulus cucumerisand Amblyseius swirskiion Thrips palmi and Frankliniella schultzei on cucumber. Biol Control 92:85-91

Lee SH, Gillespie DR (2011) Life tables and development of Amblyseius swirskii (Acari: Phytoseiidae) at different temperatures. Exp Appl Acarol 53:17-27

Messelink GJ, Van Steenpaal SEF, Ramakers PMJ (2006) Evaluation of phytoseiid predators for control of western flower thrips on greenhouse cucumber. BioCont 51:753-768

Shipp JL, Wang K (2003) Evaluation of Amblyseius cucumeris(Acari: Phytoseiidae) and Orius insidiosus (Hemiptera: Anthocoridae) for control of Frankliniella occidentalis (Thysanoptera: Thripidae) on greenhouse tomatoes. Biol Control 28:271-281 
Stansly PA, Castillo JA (2010) Control of broad mites, spider mites, and whiteflies using predaceous mites in open-field pepper and eggplant. Florida State Hort Soc 122:253-257

van Houten YM, Ostlie ML, Hoogerbrugge H, Bolckmans K (2005) Biological control of western flower thrips on sweet pepper using the predatory mites Amblyseius cucumeris, Iphiseius degenerans, A. andersoni and A. swirskii. IOBCWPRS Bull 28:283-286

Venette RC, Davis EE (2004) Chilli thrips/yellow thrips, Scirtothrips dorsalis hood (Thysanoptera: Thripidae) mini Pest risk assessment. University of Minnesota St. Paul, p 31

Wang Z, Hou W, Hao C, Wu Q, Xu B, Zhang Y (2011) Monitoring the insecticide resistance of the field populations of western flower thrips, Frankliniella occidentalis in Beijing area. Chinese J Appl Entomol 48:542-547

Webster C, Reitz SR, Perry K, Adkins S (2011) A natural M RNA reassortant arising from two species of plant- and insect infecting bunya viruses and comparison of its sequence and biological properties to parental species. Virol 413:216-225

Yang XM, Lou H, Sun JT, Zhu YM, Xue XX, Hong XY (2015) Temporal genetic dynamics of an invasive species, Frankliniella occidentalis (Pergande), in an early phase of establishment. Sci Rep 5. https://doi.org/10.1038/srep1187

Zhao M, Ho H, Wu Y, He Y, Li M (2014) Western flower thrips (Frankliniella occidentalis) transmits maize chlorotic mottle virus. J Phytopathol 162:532-536

\section{Submit your manuscript to a SpringerOpen ${ }^{\odot}$ journal and benefit from:}

- Convenient online submission

Rigorous peer review

- Open access: articles freely available online

- High visibility within the field

- Retaining the copyright to your article

Submit your next manuscript at $\gg$ springeropen.com 